\title{
Social networking as an advertising tool in Russia and abroad
}

\author{
Y. A. Ageeva ${ }^{4}$, I.V. Kondratyeva ${ }^{1, a}$, Z.S. Zavyalova ${ }^{1}$, E.V. Giniyatova ${ }^{1}$, M. P. Zavyalova ${ }^{2}$, Ann K. Deakin ${ }^{3}$, Y.V. \\ Lokotosh $^{1}$ \\ ${ }^{1}$ Tomsk Polytechnic University, 634050 Lenin Avenue, 30, Tomsk, Russia \\ ${ }^{2}$ Tomsk State University, 634050 Lenin Avenue, 36, Tomsk, Russia \\ ${ }^{3}$ State University of New York, 280 Central Ave, Fredonia, USA. \\ ${ }^{4}$ Tomsk Administration, 634050, Lenin Avenue, 73, Tomsk, Russia
}

\begin{abstract}
This study contrasts the behavioural patterns of users on Facebook with those on VKontakte using data collected by Facebook and a survey of Russian VKontakte users. The authors analyse the key differences between the two popular social networks, including what users perceived to be the most attractive options, the amount of time spent online and attitudes toward advertising. The results have been used to evaluate the potential of social networks (SMM) for business promotion in Russia.
\end{abstract}

\section{Introduction}

Before setting out to consider social networking as an advertising tool, we have to elucidate what is implied by the terms "social network" and "social media" in a broad sense. Differentiation is often difficult to do because it involves several different aspects of the terms mentioned.

We should differentiate the so-called "traditional" networks and media from those that use Web 2.0 as a platform. Lon Safko and David Brake in their book The Social Media Bible reveal the essence of their social ecosystem concept. The authors think that a biological ecosystem presents a complex association of living organisms interacting with one another. Each separate member of the association as well as the collective population of organisms sees itself as one of the components of the system. Some organisms cooperate while others compete for the resources necessary for survival [1]. The same principle can be applied when considering the relationships in social networks based on Web 2.0. The full name for such networks is Social Networking Sites (SNS).

SNS, like any other social form of communication via the Internet, is a historically new type of communication where message content producers enter the relationship with the consumers of these messages, who are thus getting involved in its further production, and each reader can perform the author's functions, acting as a comment maker, reporter, photo-reporter or editor of this service. Thus, SNS appear as a mirror of postmodernist culture, where the author and the reader overlap [2].

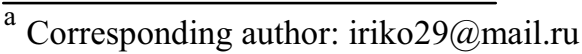

SNS mark the initial stage of the new communication era where people can communicate using informationcommunication technologies (ICT) to achieve different goals. Participants of electronic communication can share knowledge, experiences, opinions, news, videos, photos, music, and links to websites to establish and develop contacts.

Andreas Kaplan and Michael Haenlein define social media as "a group of Internet-based applications on a particular ideological and technological basis of Web 2.0, allowing participants to communicate in social networks and to create the so-called "user-generated content" [3].

At the same time, Web-based social media with their enormous manipulative potential are seen as a fundamentally new and highly effective means of concentration of power. According to some claims, unlike traditional media, based on institutionalized authority, Web-based social media appeal to the sense of belonging to a particular community.

Safko and David Brake mentioned in their book that many people tend to confuse the concepts of social networks and social media, and often use them interchangeably. But the authors, like the majority of American researchers indicate that there is a difference between social media and social networks. In their opinion, online social media can be considered as a broadcasting strategy, while social networks are the tools and utilities to communicate with other people. "The difference is not just semantics but in the features and functions put into these websites by their creators, which dictates the way they are to be used." [4].

Bedell reports that the key difference between social media and SNS is the communication style: social media 
is a channel for communication, not a location you can visit, while, by contrast, social networking is a two-way communication, where conversations are the essential part since they make up the network itself [5].

Thus, the American scientific school considers SNS one of the main categories of social networking media. Their definition of social media and SNS is more often functional, while Russian researchers think that any social network basically is aimed at building a community of people with similar interests and/or activities. Social networks are not just online social tools such as Facebook or Vkontakte; they have also a classical meaning, i. e. the meaning of social network in sociology - a social structure consisting of a group of people and organisations with social links between them (social relationships) [6].

Contrary to the functional view of the American scientific school, the understanding of Russian researchers is semantic.

The difference of aspects that are taken for the key ones when regarding social media and SNS in Russia and abroad has also been influencing the structure and functional characteristics of Russian-speaking and English-speaking SNS. Since we explore the potential of SNS in Russia for marketing, it is especially important to reveal the specific features of Russian-speaking SNS, which can have a crucial effect on business promotion. Among the features we mentioned in our earlier research $[7,8]$, we believe the most influencing one is that Russian-speaking SNS focus on communication rather than on business.

In the West, social media has ceased to be limited to messaging between users and has become a powerful promotional tool. The social and economic significance of the phenomenon is studied by international researchers such as J. Falls, J. Jarvis, S. Trattner, F. Kappe, Li Charlene, J. Bernoff M. Stelzner, L. Webber and Russian scholars A. Senatorov, D. Halilov, E.Lisovsky, K. Maksimyuk, and P. Sadovnikov, among others. All agree that Social Media Marketing (SMM) is a viable method for the promotion of companies and is a relevant strategy not only for the world's major brands, but also for small and medium-sized enterprises.

According to a Crowdspring study, $61 \%$ of small businesses attract new customers through social media, and a survey of 700 marketers from all over the globe, conducted by Wildfire App, has confirmed the effectiveness of social networks as a tool for promoting products and services. At the same time, $88 \%$ of respondents considered brand recognition as the most important advantage of Social Media Marketing [9]. It is, however, necessary to determine a target audience (users) based on territorial location and preferred online activities in order to successfully promote those goods and services.

In this regard, the goal of this study is to describe Russian behavioural patterns in social networks in an effort to improve the effectiveness of company promotion of products and/or services in the Russian market. To achieve this goal, we should identify the instruments that provide information about the effectiveness of SMM-promotion, summarize the characteristics of Russian and international social media and analyse the results of the survey of Russian social network users as compared to American users.

\section{Materials and methods}

To identify the preferred activities of the users of the social network "Vkontakte", we conducted a survey of 300 randomly selected respondents. Respondents were students and university employees aged 18 to 70 . The questionnaire asked respondents about their age, gender, use of "Vkontakte", the amount of time spent online, attention paid to advertising, attitudes toward advertising, and whether the respondent reposted that advertising. Answers were collected for 3 weeks, and then processed using the Statistical Package for the Social Sciences "SPSS 22.0". The results obtained were compared with the data from the study of Americans' activity on Facebook ("How are people using Facebook Survey").

\section{Results and discussion}

Currently, SMM, as used by businesses, is focused on dissemination of information about the company or a product, interaction with the target audience, reputation management and work with negative reviews. [10]. To ensure the effectiveness of SMM promotion, it is necessary to observe the following rules: frequent content updating, providing unique information meaningful to the target audience, working with similar communities, and rapid responses to user questions and comments to foster an interactive environment [11].

In addition to these universally accepted recommendations, an SMM campaign should also consider how users behave online. For example, the average Russian spends twice as much time on social networks than the American. Businesses may, therefore, give preference to Russian social media, such as "VKontakte" and "Odnoclassniki" (Classmates). The audience for businesses at these sites include 47 million and 40 million users, respectively, while the number of Russian-speaking users on Facebook and Twitter include 8 million and 3 million users, respectively.

"VKontakte" is not only the most popular network in Russia, but it is also a unique platform for SMM marketing which is explained by several factors. Firstly, it has more than 40 million thematic groups (communities) that allow users to communicate and receive information. Secondly, "VKontakte" has an easily customized interface for the administrator of a group. It has more options like adding documents and audio files or conducting surveys. (For reference, the option to conduct a survey has been removed from Facebook). [12] Thirdly, "VKontakte" has a large and heterogeneous audience that differs in sociodemographic characteristics and age. Overall, it contributes to more effective targeting, as users on "VKontakte" fill their profile in more detail, revealing more personal information. 
"VKontakte" also has a number of disadvantages, including a younger audience than on Facebook or "Odnoklassniki" and the factor of force-majeure related to the systematic introduction of new rules that fundamentally change the strategy and tactics of promotion, thus making it extremely difficult to plan a long term campaign.

On the contrary, Facebook, so widely-spread in the United States [13], has not become truly popular in Russia, although it has been developed in the Russianspeaking segment. This is explained by the specific interface and behaviour of the audience as well as the socio-demographic characteristics of the users. The Facebook interface is not easy for a new user to understand, and the average user age is older than on Vkontakte. The Russian-speaking segment of Facebook is popularized mainly by marketers, IT-specialists and managers, that is, people who have a large number of contacts abroad and, typically, a good education and a higher income than the audience on "VKontakte," which includes a much broader range of users.

As might be expected, Facebook is a more expensive network. Expenses for each new user on it are much higher than those on other social networks. As a result, from a marketing perspective, Facebook in Russia remains more focused on the image effect, rather than on sales. Perhaps, one of the most distinct differences is that Facebook makes it popular to identify oneself with a brand. People are willing to join the community, which was originally dedicated to a popular brand, while users on "VKontakte" users prefer to enter the unpopular communities. Due to its features, Facebook more successfully promotes such goods and services as electronic gadgets and other IT-products, online services, travel deals, B2B (business-to-business) with broad potential target audiences (advertising, IT-solutions, financial services and so on), education (in particular, business education), finance, automobile industry; books (especially business literature), fashion industry, show business and film industry $[14,15]$.

Most companies prefer to have accounts on several networks, but the principle of covering what is possible does not seem to work with social media, because the demography and behavioural patterns differ in each network. Our study has shown the key differences of how people are using Vkontakte and Facebook. The results are presented in the table below.

Table 1. The data on the use of "Vkontakte" and Facebook

\begin{tabular}{|c|c|c|}
\hline & VKontakte & Facebook \\
& & \\
\hline \multirow{3}{*}{ User age } & $18-24$ years old & $25-34$ years \\
& $-53 \%$ & old $-46 \%$ \\
& $25-50$ years old & $35-50$ years \\
& $-32 \%$ & old $-52 \%$ \\
\hline \multirow{3}{*}{ Gender } & Women - & Women - \\
& $52,8 \%$ & $57,3 \%$ \\
& Men $-47,2 \%$ & Men $-42,7 \%$ \\
\hline
\end{tabular}

\begin{tabular}{|c|c|c|}
\hline Time spent online & $\begin{array}{c}49 \% \text { - I live on } \\
\text { it } \\
38,6 \%-1,2 \\
\text { hours a day } \\
12,4 \%-10-15 \\
\text { min a day }\end{array}$ & $\begin{array}{c}19,7 \% \text { - I live } \\
\text { on it } \\
42,8 \%-1,2 \\
\text { hours a day } \\
37,5 \% \text { - } 10-15 \\
\text { min a day }\end{array}$ \\
\hline $\begin{array}{l}\text { Attention to } \\
\text { advertising }\end{array}$ & $\begin{array}{l}9 \% \text { - regularly } \\
27,5 \% \text { - never }\end{array}$ & $\begin{array}{c}6,8 \% \text { - } \\
\text { regularly } \\
28,3 \% \text { - never }\end{array}$ \\
\hline Attitude to advertising & $\begin{array}{c}47,5 \% \text { - loyal } \\
52,5 \%- \\
\text { negative }\end{array}$ & $\begin{array}{c}60,7 \% \text { - loyal } \\
39,3 \%- \\
\text { negative }\end{array}$ \\
\hline $\begin{array}{l}\text { Participation in } \\
\text { spreading } \\
\text { advertisement }\end{array}$ & $\begin{array}{l}28 \% \text { - make } \\
\text { reposts } \\
72 \% \text { - no }\end{array}$ & $\begin{array}{c}52,9 \% \text { - make } \\
\text { reposts } \\
47,1 \% \text { - no }\end{array}$ \\
\hline
\end{tabular}

The main findings of the study are the following:

-The gender composition of the audience is about the same for both social networks, with an almost equal proportion of male and female users. But the age data is markedly different. "VKontakte" is dominated by users ranging in age from 18 to 35 years old, while on Facebook, there are more people in the older age ranges. According to a study by the Pew Research Center, $48 \%$ of respondents aged $65+$ are actively using this particular social network [16]. The degree of attention paid to advertising is reported to be almost identical for both networks.

- The Russian audience on "Vkontakte" is less loyal to advertising (47.5\% against $60.7 \%$ of Facebook). We can assume that a negative attitude to advertising arises from its being intrusive and of low quality.

- Reposting is directly dependent on the attitude of users to advertising. More than a half of the audience on Facebook have a positive attitude to this kind of promotion, and only $28 \%$ users on Vkontakte report to be making reposts.

- Almost half the audience (49\%) on VKontakte is on-line all day, while the same category on Facebook is only $19.7 \%$. This difference is directly related to the fact that Russians have a more multifunctional approach in their use of social networks. During the survey, we also asked respondents to rank activities they are fond of on Vkontakte in order of importance. As a result, we have obtained the following order:

1. Connecting with friends;

2. Reading the news;

3. Listening to music and watching videos;

4. Searching for information about companies, products, services;

5. Playing games.

This information can be especially useful for marketers to choose how to present and target their advertising on Vkontakte.

\section{Conclusion}

Summing up the results of the study, we can say that, despite the fact that the search for information about the 
products and services is not popular either on Vkontakte or on Facebook, both networks can still be considered as convenient platforms for advertising. The only pro is that there are a certain number of users who deliberately look for advertising, but the possibility to cover the other categories of potential customers is even more promising. In this respect, social networks are catching up with the largest search engines such as Google and Yandex [17].

At the same time we have found out that Facebook has little potential for the promotion of business in Russia. If audiences are small, they are difficult to target. Facebook is more suitable for large-scale businesses or B2B.

The social network "VKontakte" has a huge stock of user loyalty [18]. Despite the fact that there are many new social networks, the outflow of customers from "VKontakte" is minimal. The findings of how people behave on Vkontakte and what kinds of activities they prefer can help companies to choose the proper way of presenting and targeting their products and services for Russian customers.

\section{References}

1. L. Safko, D.K. Brake, The social media bible: tactics, tools, and strategies for business success. (Hoboken, N. J.: John Wiley \& Sons. XVIII, 2009).

2. Z.S. Zavyalova Bulletin of Tomsk State University, 343 (2011).

3. Kaplan, Andreas M.; Michael Haenlein, Business Horizons, 53 (1), 59-68 (2010)

4. L.S. Cohen, Retrieved January $30 \quad$ (2016) http://lonscohen.com/blog/2009/04/differencebetween-social-media-and-social-networking/

5. J. Bedell, Retrieved February 4 (2016), from JTB Consulting : http://jasontbedell.com/whatisthe-difference-between-social-media-andsocial-networking

6. Di Chen, Vestnik SPSU. 9 (2012).

7. Yuliya Ageeva, Zinaida Zavyalova, Journal of Economics and Social Sciences. 6 (2015)

8. Irina Vladimirovna Kondratyeva (Kondratieva), Procedia - Social and Behavioral Sciences, 166, 562-565 (2015)

9. Social'nye media - neobhodimost' dlja malogo biznesa. $\quad-\quad$ URL: http://www.sostav.ru/blogs/57918/7775/ (Retrieved: 03.05.2015)

10. SMM kak moshhnyj instrument prodvizhenija. URL: http://www.welcomseo.ru/blog/smm-kakmoshchnyy-instrument-prodvizheniya-vinternete.htm (Retrieved: 10.05.2015)

11. D. Halilov, Marketing v social'nyh setjah (M.: Mann, Ivanov i Ferber, 2014).

12. Zolotye pravila SMMshhika. - URL: http://frilka.com/zolotye-pravila-smmshhika-ilismm-kak-na-ladoni/ (data obrashhenija, 19.05.2015)

13. Ne nado zanimat'sja SMM iz-za togo, chto jeto modno.

URL: http://www.therunet.com/articles/3708-ne-nado- zanimatsya-smm-iz-za-togo-chto-eto-modno (data obrashhenija, 19.05.2015)

14. How Are People Using Facebook - URL: https:/www.stonetemple.com/how-are-peopleusing-facebook/ (data obrashhenija: 06.05.2015)

15. Internet User Demographics. - URL: http://www.pewinternet.org/data-trend/internetuse/latest-stats/

16. Maeve Duggan. The Demographics of Social Media Users http://www.pewinternet.org/2015/08/19/thedemographics-of-social-media-users/

17. Facebook dogonyaet Google $v$ mobilnoj reklame http://news.senfil.net/?newsid=1303

18. Anastaciya Matveeva, 43 minutyi $v$ den rossijskie polzovateli provodyat VKontakte http://www.searchengines.ru/news/archives/43_min uty_v_den.html 